\title{
Associação de Arquivistas no Brasil na década de 1970
}

\author{
Eliezer Pires da Silva \\ eliezerpires@gmail.com \\ Evelyn Goyannes Dill Orrico \\ orrico.evelyn@gmail.com
}

Universidade Federal do Estado do Rio de Janeiro (UNIRIO)

Resumo: A criação da Associação dos Arquivistas Brasileiros, seguida da constituição de seu instrumento periódico de divulgação e da organização do seu fórum bianual são elementos que revelam as características de um plano coordenado de ações. A finalidade foi dignificar o trabalho arquivístico, delineada estatutariamente em três dimensões: formação para a ocupação nos arquivos, legalização profissional da competência e regulação nacional dos arquivos. $O$ processo de profissionalização revela uma competência que vai se delimitando em torno da preocupação com a qualidade de determinado trabalho, em prol da sociedade, e de sua regulação pelo Estado. Nesse sentido, a configuração do campo arquivístico no Brasil se relacionaria, portanto, com a passagem da condição de ocupação à de profissão, regulamentada por lei federal e apoiada nos cursos universitários de arquivologia. Visto dessa forma, a institucionalização do campo arquivístico no Brasil parece ser uma realização - e também o esgotamento da agenda - do associativismo instituído através da Associação dos Arquivistas Brasileiros, em 1971, com a finalidade assumida de estabelecer um modelo nacional de institucionalização da arquivologia (curso universitário), do arquivista (profissão de quem fez essa graduação) e dos arquivos (legislação arquivística).

Palavras-chave: Arquivologia; arquivista; associação de arquivistas;

\begin{abstract}
The creation of the Associação dos Arquivistas Brasileiros, followed by the launching of its periodic instrument of dissemination and by the organization of its biannual forum are elements that show the characteristics of a coordinated plan of action. The purpose was to honor archival work, statutorily delineated in three dimensions: training for working in the archives, professional legalization of archival work and national regulation of the archives. The professionalization process reveals a competence that is built around the concerns with the quality of a certain work on behalf of society, and of its regulation by the State. Accordingly, the configuration of the archival field in Brazil would relate, therefore, with the change from the condition of an occupation to that of a profession, regulated by federal law and supported by archival university courses. Considered this way, the institutionalization of the archival area in Brazil seems to be an achievement - and also the depletion of the agenda - of the associativism established through the association of archivists, in 1971, with the declared purpose of establishing a national model for the institutionalization of archival studies (at university level), of the archivist (profession of someone who attended an undergraduate course) and of the archives (archival legislation).
\end{abstract}

Keywords: archival studies; archivist; association of archivists. 


\section{INTRODUÇÃO}

Os anos de 1970 no Brasil, em pleno regime político autoritário, foram marcados por amplo desenvolvimento econômico, mas também por problemas tanto na trajetória profissional dos trabalhadores quanto na sua atuação política, na medida em que essas duas frentes de atuação compartilhavam reivindicações, quase sempre mal recebidas pelo regime militar. Com base em revisão de literatura, interpreta-se que processo histórico fomentou complexa formação de identidades, sociabilidades e de redes de solidariedade nos mecanismos de coesão social do movimento de arquivistas.

Essa contextualização histórica fundamenta parte da pesquisa do projeto em andamento Memória e discurso-informacional de instituições sobre a institucionalização do campo arquivístico no Brasil, no âmbito do Programa de Pós-Graduação em Memória Social da Universidade Federal do Estado do Rio de Janeiro - Unirio, dentro da linha de pesquisa Memória e Linguagem e por isso o objetivo deste artigo é caracterizar, a partir dos autores que estudam o associativismo brasileiro, as condições de possibilidade para a organização coletiva dos arquivistas na década de 1970. Toma-se aqui o conceito de Norberto Bobbio para quem as associações são:

Uma entidade organizada de indivíduos colegiados entre si por um conjunto de regras reconhecidas e repartidas, que definem os fins, os poderes e os procedimentos dos participantes, com base em determinados modelos de comportamentos oficialmente aprovados. (BOBBIO; MATTEUCCl; PASQUINO, 2002, apud FONSECA, 2008, p. 15).

Este texto apresenta algumas concepções teóricas sobre o associativismo, mais diretamente sobre o panorama relativo ao fenômeno associativo brasileiro e, em especial, sobre o modo como se desenvolveu o associativismo arquivístico no Brasil da década de 1970.

\section{O QUE É ASSOCIATIVISMO}

Alexis de Tocqueville foi o pensador pioneiro na compreensão do associativismo para fortalecimento da democracia. Na publicação Democracia na América, de 1835, esse autor caracteriza a sociedade norte-americana de sua época, enfatizando sua organização por meio de associações civis. Tocqueville interpretou esse traço da sociedade civil norte-americana como a arte da associação. A teoria política de Tocqueville pressupõe uma perspectiva histórica de evolução das sociedades ocidentais na direção da maior igualdade. 
A democracia como processo no qual a igualdade se afirma, segundo Tocqueville, comporta também os riscos da tirania da maioria na medida em que há diminuição da participação política das pessoas. Desse modo, a igualdade de condições provocaria uma visão de maiores benefícios na esfera privada em relação com a esfera pública.

Segundo Tocqueville ${ }^{1}$ (1998, p.391-2 apud GANANÇA, 2006, p. 17),

\begin{abstract}
Americanos de todas as idades, de todas as condições, de todos os espíritos, estão constantemente a se unir. Não só possuem associações comerciais e industriais, nas quais todos tomam parte, como ainda existem mil outras espécies: religiosas, morais, graves, fúteis, muito gerais e muito particulares, imensas e muito pequenas; os americanos associam-se para dar festas, fundar seminários, construir hotéis, edificar igrejas, distribuir livros, enviar missionários aos antípodas; assim também, criam hospitais, prisões, escolas [...] Assim, o país mais democrático da terra verifica-se ser aquele onde os homens mais aperfeiçoaram hoje em dia a arte de procurar em comum o objeto dos seus comuns desejos e aplicaram ao maior número de objetos essa ciência nova.
\end{abstract}

Nota-se que Tocqueville apresenta o fenômeno associativo nos Estados Unidos como o agrupamento de pessoas sob um interesse comum a partir de uma sociabilidade formal e institucionalizada sem reivindicação do poder político, ou seja, enfatiza a prática de colaboração e solidariedade.

\begin{abstract}
Nos países democráticos, a ciência da associação é a ciência mãe; o progresso de todas as outras depende dos progressos daquela. Entre as leis que regem as sociedades humanas, existe uma que parece mais precisa e mais clara que todas as outras. Para que os homens permaneçam civilizados ou assim se tornem, é preciso que entre eles a arte de se associar se desenvolva e aperfeiçoe na mesma medida em que cresce a igualdade de condições. (TOCQUEVILLE, 1998, p.394 apud GANANÇA, 2006, p. 18 ).
\end{abstract}

Essa interpretação confere um papel fundamental ao associativismo para viabilizar um regime democrático. Em 2008, Vitor Manoel Marques da Fonseca defendeu tese de doutorado em História na Universidade Federal Fluminense sobre as características e as finalidades do associativismo, com base nas associações com personalidade jurídica no Rio de Janeiro entre 1903 e 1916. Para ele, essas entidades têm como finalidade solucionar problemas bem concretos da população.

Nesse sentido, o associativismo será um dos mecanismos utilizados pelos indivíduos para realização de uma cidadania mais ampla. Reunidos em torno dos mesmos interesses, por meio das associações, congregam seus esforços,

\footnotetext{
${ }^{1}$ TOCQUEVILLE, Alexis de. A democracia na América. 4.ed. Belo Horizonte: Itatiaia, 1998.
} 
dão visibilidade à sua luta, configuram interlocutores mais fortes no debate com o restante da sociedade e com o Estado, ampliando as possibilidades de mudança da realidade social como um todo. (FONSECA, 2008, p. 203)

Ao identificar a trajetória do associativismo inglês, norte-americano e francês, Fonseca assinala que, na Inglaterra, as associações teriam entrado em crise no final do século XIX, na medida em que se difundiu a ideia de que o Estado deve prover as bases sociais do bem-estar dos cidadãos. Com base nos estudos de Alexis de Tocqueville, apresenta os mecanismos norteamericanos de ação coletiva como único meio de agir, combinando individualismo e bem comum. No caso da França, ressalta o entendimento de que o associativismo é a condição fundamental da mediação de grupos secundários na relação entre Estado e cidadão.

Ainda segundo Fonseca, as associações recorrem a diferentes formas de divulgação. As publicações podem ter o formato de folhetos, revistas, informes, relatórios e boletins.

Independentemente do conteúdo, das tiragens, da distribuição, da periodicidade e da perenidade ou não das publicações [...] as associações viam os veículos impressos como meios eficientes de atingir seus associados, a sociedade e o Estado, ainda que, na prática, as dificuldades financeiras restringissem fortemente a possibilidade de publicarem. (FONSECA, 2008, p. 198)

Em nosso projeto de pesquisa pretendemos explorar, em outro momento, como tais publicações das associações são fontes privilegiadas sobre seus discursos. Existem várias visões teóricas sobre o papel do associativismo, frequentemente, vinculadas a uma teoria sobre o convívio democrático. Numa compreensão democrática liberal, a ampla participação política deve dar lugar ao associativismo com a função de manter a estabilidade do sistema político por meio da agregação e expressão de interesses individuais na esfera pública.

$\mathrm{Na}$ relação com o Estado brasileiro, as associações representam a sociedade civil organizada a partir de marcos legais construídos ao longo de regimes políticos durante o século XX até a Constituição de 1988.

O mapeamento e a classificação do associativismo no país realizado por Ganança (2006) revela uma infraestrutura organizacional a partir de dados estatísticos, pelo critério da figura associativa definida no Código Civil e na Lei de Registros Públicos como uma pessoa jurídica de direito privado, institucionalizada, devidamente registrada nos cartórios de registro civil de pessoas jurídicas, constituídas livremente pela união de pessoas em torno de uma finalidade não econômica ou não lucrativa. Os dados da pesquisa revelam aproximadamente 276 mil associações civis no país em 2002, com 1,5 milhão de pessoas empregadas, sendo a maioria (62\%) constituída a partir de 1991. 
O crescimento recente do número de associações civis no país está associado ao processo de abertura política, os incentivos estatais direcionados para as associações civis (agricultura, organizações indígenas), formalização de grupos populares ou de trabalhadores para o acesso a certos benefícios, conselhos setoriais de políticas públicas dentro do Estado e alternativa de organização flexível do trabalho frente ao desemprego (GANANÇA, 2006).

Embora o tema da organização da sociedade civil por meio do associativismo venha sendo debatido em diversas áreas das ciências humanas e sociais, concordamos com Gohn (2010) quando afirma que esse tema precisa ser contextualizado no tempo e no espaço em que sociedade civil e Estado estão em relação.

\section{ASSOCIAÇÕES NO BRASIL NA DÉCADA DE 1970}

De acordo com Oliveira (2010) o impacto do associativismo no Brasil da década de 1970 tem sido interpretado pelos extremos: de um lado, há quem negue a sua efetividade supondo um processo de transição operado por grupos dominantes sobre o fim do regime autoritário; por outro, há os que reconhecem a força da mobilização popular por intermédio dos próprios instrumentos de organização social instituídos por governos populistas, sobretudo, anteriores ao regime militar.

Na proposta de Ramalho (2000), a interpretação desse processo histórico demanda também uma discussão que articule a formação da identidade, e de redes de sociabilidade, para além da preocupação com as contradições entre as "leis do mercado" e os mecanismos de "coesão social" no movimento dos trabalhadores.

Para Ganança (2006), o fenômeno da ação coletiva institucionalizada no Brasil revela a influência do Estado, exercida por meio do marco legal aplicável a associações civis, na formatação, na burocratização e no incentivo desse tipo de ação coletiva.

Os anos de 1970, dentro do regime político autoritário no Brasil, foi um período de evidente perseguição oficial aos ativistas políticos no país. Apesar das condições diferenciadas nas quais as categorias profissionais experimentaram o "arrocho salarial", esse foi o terreno no qual trabalhadores foram mobilizados em torno de campanhas salariais, luta pelo retorno da democracia no país e recusa da tutela do Estado na negociação com o empregador. Os anos 70 seriam um cenário de atuação sindical com diretrizes radicais discursadas pelas diferentes categorias (SANTANA, 2003).

Para Santana (1999, p. 104) o movimento dos trabalhadores experimentou uma supressão do espaço de ação depois do golpe militar de 1964, restringindo-se ao interior das fábricas. Esse quadro se reverteria dez anos mais tarde, na medida em que "a reemergência do 
movimento dos trabalhadores estremeceu os arranjos políticos da transição para o regime democrático que iam sendo articulados sem levá-lo em consideração".

De maneira ampla e panorâmica, alterou-se o quadro de coletividades excluídas da esfera política, ao mesmo tempo em que emerge o movimento dos trabalhadores com a criação de associações de profissionais de classe média exercendo o papel de ator político nos anos 70. Houve uma reconfiguração nos padrões de controle do Estado sobre a atividade sindical combinada com a busca de alternativas para a organização coletiva por meio das associações.

Nessa direção impõe-se a seguinte questão: quais são os principais traços dessa condição histórica dos anos 70 que limitam, mas ao mesmo tempo possibilitam a ação coletiva no mundo do trabalho? Uma resposta possível seria adotar o associativismo como possibilidade de convívio democrático. No entanto, com base em Ganança (2006), afirmamos que as características do universo associativo no Brasil revelam limitações para a construção de uma realidade democrática e participativa no país.

Embora tal afirmação vá de encontro ao que diferentes perspectivas teóricas afirmam sobre o papel do associativismo, já que defendem ser recorrente vinculá-lo à participação democrática orientada por princípios ético-políticos pactuados e coletivamente compartilhados, compreendemos que o fenômeno associativo brasileiro sugere uma diversidade nas características democratizantes e participativas, expressando a complexidade política e cultural daquele contexto histórico.

No livro A arte da associação, Boschi (1987) aborda o fenômeno associativo sob condições políticas repressivas no Brasil, enfatizando as formas urbanas de mobilização na década de 1970. Reconhece nesse contexto a presença de elementos de instabilidade suficientes tanto para aprofundamento do autoritarismo quanto para democratização no país. Do ponto de vista da mobilização haveria uma inédita generalização de coletividades emergentes em torno de valores democráticos. Constata dois aspectos em paralelo de uma agenda democrática: primeiro, a abertura "gradual" das instituições políticas, segundo, o modo como o convívio democrático era reinventado no interior de coletividades que buscavam alternativas para se contrapor ao autoritarismo.

Nessa direção, como funcionava esse processo de mobilização na organização e na representação de interesses dos diferentes segmentos sociais? Ao acompanhar a dinâmica dos movimentos de base em diferentes cidades Boschi (1987) observa uma práxis cotidiana de apropriação de mecanismos institucionais no enfrentamento com o Estado, mas, também, uma rejeição às formas tradicionais de atuação política. Uma tensão que envolvia como 
manter autonomia sem abrir mão dos êxitos que resultam do envolvimento na lógica do Estado.

O que haveria de novidade nas formas de intervenção do Estado e nos esforços de construção de solidariedade e criação de identidades no Brasil da década de 1970 ? O processo de redemocratização em questão tem sido cada vez mais problematizado numa abordagem interativa entre os estudos sobre política brasileira que tendem a enfatizar de modo unilateral o Estado, de cima para baixo, pelo viés de mudanças institucionais cuidadosamente geridas, e as análises do impacto político das iniciativas de organizações coletivas e da dinâmica dos movimentos sociais sobre a ordem política, de baixo para cima.

Ao se contextualizar as interpretações sobre o papel das associações e como "as novas identidades coletivas terminam por expressar novos alinhamentos sociais e as pressões para a incorporação de núcleos de interesse até então excluídos" (BOSCHI, 1987, p.24) deve-se considerar a inovação na autonomia dessas práticas coletivas e, ainda, o quanto reproduzem normas e valores dominantes por intermédio da mediação institucional de que laçam mão.

As associações como estilo de atuação política não ultrapassam as dimensões coercitiva e institucional da ação coletiva, no entanto, enfatizam ser uma busca por soluções autônomas para afirmar identidades coletivas ainda não consideradas legítimas, negam ser uma tentativa de tomada do aparelho de Estado. Frequentemente estão inscritas numa constatação de crise do sistema partidário como lócus principal de participação política.

Embora exista um componente emancipatório nessa possibilidade de fazer emergir novas identidades coletivas, isto não significa que, uma vez constituídas, as novas coletividades não impliquem tendências opressivas, tanto para seus membros como para os que estão fora (ou assim querem permanecer) (BOSCHI, 1987, p. 31).

Apesar dos autores compartilharem uma representação de imponderável para o impacto da ação coletiva, o desafio que se estabelece é compreender o nível da institucionalização em relação à base social de conflitos que lhe oferece contexto, instituições podem ser instrumentos que tornam obscuras as regras do jogo que sancionam relações de dominação. As condições de emergência dos movimentos sociais não são uma evidência dada às análises.

É comum a ideia de que os movimentos sociais são o surgimento de identidades coletivas em resposta ao descrédito aos arranjos institucionais vigentes para o exercício da política, funcionariam como meio de escapamento dos interesses de minorias ou marginalizados da sociedade. No contexto autoritário, e em transição, como se pode caracterizar o Brasil da década de 1970 cabe afirmar, genericamente, que houve liberdade de associação e os movimentos atuaram contra a centralização do processo de decisão, os 
movimentos sociais se tornaram meios de expressão coletiva para concretizar metas políticas fora dos canais oficiais do Estado. Nesse sentido, ainda, "As organizações [instituições políticas] são apontadas como limitando a liberdade, em sua tendência à hierarquização e estratificação, as quais implicam o controle" (BOSCHI, 1987, p. 37).

Nesse período, o fenômeno da ação coletiva nas regiões metropolitanas brasileiras, envolvendo "classes populares", é um universo representativo de emergência de novos atores políticos e de um padrão de participação que procura se contrapor aos parâmetros institucionais vigentes. Na década de 1970 ganham força as manifestações coletivas por intermédio de associações comunitárias como instrumentos de expressão de protestos e demandas na esfera pública. Mas como compreender os efeitos político-institucionais desse tipo de ação coletiva?

Para Boschi (1987) essa atuação coletiva resulta do enfrentamento com o Estado, buscando abrir espaços para representar interesses então excluídos da arena política. Nesse sentido a associação significa um estágio no processo de mobilização como uma espécie de monopólio legítimo de representação para a organização dos protestos numa rede de comunidades de base nas diversas regiões do Brasil.

As associações encontraram dificuldades para manter níveis altos de participação regular na medida em que "o contato com o Estado leva à expansão do movimento e eventualmente impede alguns de seus desdobramentos, numa lógica de ação controlada pelo alto" (BOSCHI, 1987, p. 57). Por outro lado, as organizações coletivas inscritas no crescimento urbano "desproporcional" da década de 1970 ultrapassam a possibilidade de serem um padrão presidido pelo Estado.

A análise dos processos históricos e sociais que presidem a organização e o funcionamento de instâncias coletivas de ação no Brasil da década de 1970 revela ainda a importância da expansão de profissões técnicas assalariadas no período e seu papel enquanto ator coletivo. Boschi (1987) observou um crescimento de $80 \%$ nas ocupações burocráticas e técnico-científicas entre 1970 e 1980.

O Rio de Janeiro se apresenta como uma significativa experiência dentro do processo de constituição de associações no Brasil, desde as organizações de assistência mutualista ainda no século XIX. Na década de 1970 houve um fenômeno de mobilização envolvendo a criação de associações em bairros de classe média mais voltadas para o controle de políticas públicas do que estabelecimento de demandas. Para Boschi (1987, p. 67):

O movimento associativo urbano nos anos 70 e 80 caracterizou-se, desde o início, não só pela oposição ao regime (embora os objetivos declarados das associações tendessem a omitir o fato), mas também, através de um forte apelo à identificação com a comunidade local, pela presunção política de 
tornar possível um espaço institucional alternativo tanto para acesso ao

Estado como para a concretização dos princípios democráticos.

As evidentes restrições à livre associação dentro de um regime de exceção conviveram com a capacidade de organização de grupos sociais em meio à repressão, em especial, o caso dos moradores de favela, que se associaram cada vez mais para defender interesses locais fundamentais. Esse associativismo comunitário parece ter sido percebido como meio de encaminhar necessidades cotidianas mais imediatas, articulando também a possibilidade de convívio democrático e a afirmação de identidades, não como expressão direta de oposição ao regime.

Nos vários tipos de associativismo, de defesa e promoção de direitos, para a organização do trabalho e o desenvolvimento de atividades produtivas, a ação coletiva institucionalizada no país pode ser observada na efetividade de direitos civis, políticos e sociais ao se observar a expressão de diversos grupos sociais na esfera pública. Por outro lado existem segmentos associativos conservadores atuantes na sociedade civil.

Os debates teóricos sobre a ação coletiva revelam uma representação comum presente na identificação da liberdade com práticas não-institucionalizadas, ao passo que se vincula o âmbito institucional à repressão. Consequentemente esse é um enquadramento do qual escapa o questionamento sobre o quanto a institucionalização de coletividades são, ao mesmo tempo, instrumento de mudanças sociais e estruturas que sancionam uma ordem estabelecida.

Os sujeitos coletivos desclassificados no quadro regulado de acesso ao Estado por intermédio dos partidos políticos e dos sindicatos, na opinião de Boschi (1987), reivindicam ser arranjos coletivos de componente emancipatório sem as limitações institucionais. A ação coletiva envolve o processo de formação e expansão do Estado e a constituição de diferentes formas de expressão política da sociedade civil. E, para ultrapassar uma abordagem utilitária da decisão individual de atuar coletivamente, esse autor defende que não se reduza "a ação coletiva ao contexto de interesses e à obtenção de benefícios concretos, desconsiderando a solidariedade e os estímulos afetivos como argamassa das relações sociais" (BOSCHI, 1987, p.18).

\section{ENTENDENDO AÇÃO COLETIVA}

A construção da realidade objetiva através das experiências coletivas revela um lugar fundamental para a coletividade, colocando em questão a emergência da própria ordem social. 
Mary Douglas (1998) expõe a força modeladora das instituições sociais na ação coletiva, os conceitos de controle social da cognição e o sistema cognitivo suprapessoal, formulados a partir de Emile Durkheim e Ludwick Flek, são utilizados para explicar como as instituições representam uma solidariedade ou ação coletiva quando os indivíduos compartilham categorias de pensamento.

Douglas (1998) decide enfrentar uma "atual visão não-sociológica da cognição humana" analisando as instituições na contramão de um comportamento racional e de soberania do indivíduo. A autora compara o relacionamento entre as mentes e as instituições em diferentes comunidades e identifica a base compartilhada do conhecimento e dos padrões morais, demonstrando o quanto o pensamento depende das instituições.

Ao discutir a natureza do laço social, mobiliza a compreensão de Emile Durkheim a respeito do conflito entre o indivíduo e a sociedade: as classificações, as construções lógicas e as metáforas do pensamento individual são de origem social. Também reconhece que essa ênfase no papel da sociedade na organização do pensamento empobreceu a esfera do indivíduo.

A orientação cognitiva das categorias de tempo, espaço e causalidade possuiria uma origem social, de acordo Durkheim. Por conseguinte, os "problemas de legitimidade são resolvidos porque os indivíduos carregam a ordem social no seu íntimo onde quer que vão, projetando-a na natureza."(DOUGLAS, 1998, p.24) Haveria uma espécie de mente grupal, "misteriosa e supra-orgânica".

Douglas apresenta as posições de Fleck sugerindo o pensamento coletivo como uma mente individual em larga escala na qual um grupo social pode pensar ou sentir. Nessa perspectiva "a sociedade constitui um todo orgânico, com vida própria, distinta e superior à vida de todos seus membros em suas relações mútuas." (RAWLS ${ }^{2}$ apud DOUGLAS, 1998, p. 26)

A autora acredita que a argumentação de Durkheim e Fleck auxiliaria na resposta à crítica funcionalista e à crítica da escolha racional porque, no fundo, desenvolve uma dupla visão do comportamento social: cognitiva e transacional.

A análise da ação coletiva deveria considerar os argumentos da escolha racional ou a cognição na formação do laço social e, também, a influência exercida pelos grupos sobre o pensamento de seus membros. Esse regime de confiança da ordem social envolveria aspectos contraditórios de justiça e moral e, no caso da pequena escala, "o indivíduo não tem muito a ganhar ou a perder permanecendo com o grupo, sua lealdade muda facilmente e ele resiste prontamente a qualquer tentativa de coerção, ameaçando cindir-se." (DOUGLAS, 1998, p.37)

\footnotetext{
${ }^{2}$ RAWLS, John. A Theory of Justice. Cambridge, Mass., Belknap, Harvard University Press, 1971.
} 
Ao pensar na sobrevivência de grupos a autora pressupõe que os sistemas de conhecimento são processos coletivos na comunidade, mas se questiona sobre como nascem os sistemas de conhecimento. Parece assumir que a ação coletiva depende do complexo entrelaçamento das múltiplas trocas recíprocas, diretas e indiretas, mas não adere à teoria da escolha racional nem ao determinismo sociológico, considerando que

Dada a pobreza das explicações alternativas, cabe-nos procurar mais cuidadosamente uma forma de argumentação funcionalista que evite tais armadilhas e, ainda assim, satisfaça as necessidades do conceito de Durkheim e de Fleck relativo a um grupo social que gera a sua própria visão de mundo, desenvolvendo um estilo de pensamento que sustente o padrão de interação. (DOUGLAS, 1998, p.43)

A questão segue sendo o problema de como se alcançar à ação coletiva. "Em vez de recorrer às crenças para explicar a coesão da sociedade, usamos a sociedade para explicar as crenças." (DOUGLAS, 1998, p.52)

Ao reverter a argumentação de consequencialidade formulada por Olson, a participação na construção do estilo de pensamento escamoteia, para cada membro do universo de pensamentos, a consequencialidade de suas próprias pequenas ações. Cada um deles acusará seu vizinho de traição sem desconfiar que um padrão de crença, comumente compartilhado, se fortalece com isso. (DOUGLAS, 1998, p.53)

Desse modo, o grupo seria coletivamente construído e o estilo de pensamento compartilhado promove a manutenção do sistema, assim, o grupo social porta um estilo de pensamento. "Na visão de Durkheim, a base coletiva do conhecimento é a questão com a qual se deve lidar em primeiro lugar." (DOUGLAS, 1998, p.57)

A autora problematiza os fundamentos de um pensamento institucional, sobretudo, o quanto as instituições conferem identidade, lembram-se e esquecem, operam classificações e tomam decisões. Aponta para uma memória pública que é um sistema de armazenamento de origem social.

Essa memória estaria apoiada pelas estruturas institucionais causando efeito sobre a cognição, uma vez que o indivíduo é um ser social sob influências sociais que o controlam seletiva, cognitiva e emocionalmente. Com base em Michael Foucault (2005), é possível demonstrar as instituições acima do pensamento individual com força de aprisionar corpos e mentes a suas convenções. As instituições dirigiriam a memória individual e as percepções com capacidade de fixar práticas e ocultar as influências exercidas sobre as emoções.

O grande triunfo do pensamento institucional é tornar as instituições completamente invisíveis. Quando os grandes pensadores de uma determinada época concordam que os dias atuais não se assemelham a 
nenhum outro período e que um grande abismo nos separa do nosso passado, temos um primeiro vislumbre de uma classificação compartilhada. (DOUGLAS, 1998, p.117)

Douglas ilustra a efetividade do domínio institucional com base nos padrões de informação e sua eficiência como meio de comunicação. Os membros compartilham um conjunto de analogias por intermédio das quais exploram o mundo e reconhecem a naturalidade e a razoabilidade numa realidade instituída.

\begin{abstract}
Assim qualquer instituição começa a controlar a memória de seus membros; ela os leva a esquecer experiências incomparáveis com aquela imagem de correção que eles tem de si mesmos e traz para suas mentes acontecimentos que apóiam uma visão da natureza que lhe é complementar. A instituição propicia as categorias dos pensamentos de seus membros, estabelece os termos para o auto-conhecimento e fixa as identidades. (DOUGLAS, p.132)
\end{abstract}

A argumentação caminha para uma discussão sobre não haver outro meio para tomada de grandes decisões que não seja na esfera das instituições. Ao avançar nessa proposta de trabalho, assumimos a noção de ação coletiva para caracterizar a rede de pessoas em torno da preocupação com os arquivos no Brasil, que foi capaz de configurar a sua relevância, bem como desenvolver um modelo de solução para essa questão no Brasil na década de 1970.

\title{
5 ASSOCIATIVISMO ARQUIVÍSTICO
}

$\mathrm{Na}$ década de 1970, realizam-se, por intermédio do associativismo arquivístico brasileiro, ações de definição de sua forma institucional: criação da Associação dos Arquivistas Brasileiros e constituição intersubjetiva de uma comunidade profissional.

A mediação construída entre o Estado e as pessoas organizadas coletivamente configura uma sociedade civil que carrega o peso da possibilidade e da impossibilidade de alcançar suas demandas. Para González de Gómez (1992), no caso dos movimentos associativos de profissionais, há uma demanda por obter reconhecimento da atividade bem como divulgar suas funções especializadas.

Para essa autora nas últimas décadas do século XX haveria o alargamento dos espaços coletivos em que os movimentos associativos reformulariam as organizações de categorias profissionais. "Iniciada como processo de construção de identidade, a formulação de um "nós" associativo dá origem a um movimento de reunião, no qual se tende a reordenar todo o campo prático-discursivo, a partir da nova posição de um sujeito coletivo" (GONZALEZ DE GOMEZ, 1992, p. 370). 
As lutas empreendidas nesses espaços de mobilização por uma profissão são um "investimento simbólico destinado a obter a jurisdição e os privilégios da competência instituída num setor específico de atividades relevantes" (GONZALEZ DE GOMEZ, 1992, p. 519). Esse movimento associativo de profissionais conseguiu instituir espaços de discurso público exprimindo as perspectivas da categoria. $\mathrm{O}$ associativismo profissional confere a um grupo social os recursos para intervir no plano das definições de uma atividade junto à sociedade e ao Estado.

Em sua dissertação de mestrado defendida em 2011, no Programa de Pós-Graduação em Memória Social da Unirio, Yuri Queiroz Gomes estudou a mobilização dos profissionais de arquivo em torno de uma associação corporativista - Associação dos Arquivistas Brasileiros (AAB). Conforme pressupomos nesta pesquisa, o associativismo é considerado decisivo para a institucionalização da área no país, reconhecendo, ainda, a falta de pesquisa acadêmica sobre o papel exercido pela a AAB entre 1971 e 1978 na organização do campo arquivístico no Brasil.

Os depoimentos recolhidos por Gomes (2011) reafirmam o projeto coletivo de regulamentação da profissão de arquivista como meio de autoafirmação dos profissionais de arquivo e formação de uma comunidade arquivística. Essa ação coletiva com sua mobilização política de conotação corporativista configurou um espaço público no qual se passa a refletir sobre a atividade arquivística, compreendendo que o trabalho arquivístico é de interesse para a sociedade e o Estado.

A formação de coletivo entre os profissionais de arquivo revela que os participantes "passaram a reconhecer um tipo específico de identidade social que se forjava na apreensão e no exercício da práxis arquivística" (GOMES, 2011, p.64), isso dentro de um contexto histórico de repressão política e reconfiguração nos padrões de controle do Estado sobre a organização coletiva no Brasil.

Esse associativismo arquivístico se caracteriza para além dos objetivos profissionais de melhoria das condições de vida e bem estar social da categoria, isso na medida em que são propositivos também diante das condições dos arquivos brasileiros. "As atividades iniciais destas associações tiveram, para além da questão corporativista, a ação direcionada à atuação dos Estados no que se refere às políticas públicas de arquivos" (GOMES, 2011, p. 85).

$\mathrm{O}$ associativismo entre os profissionais de arquivo se estabeleceu como agente articulador do agrupamento de pessoas que atuavam nessa atividade com ações destinadas ao reconhecimento profissional do arquivista e ao desenvolvimento do conhecimento técnico e científico da Arquivologia. São profissionais com suas formações de origem prática formando uma comunidade com um mesmo projeto. 
Ao estudar as relações entre associativismo, formação do arquivista e seu mercado de trabalho, Katia Isabelli Melo de Souza (2011) identifica o grande momento do movimento associativo dos arquivistas no Brasil: a criação da Associação dos Arquivistas Brasileiros, em 1971. Pressupõe ter sido um quadro de ação coletiva realizadora para promover a aprovação da graduação em Arquivologia e a regulamentação da profissão do arquivista.

De fato o modelo de organização coletiva escolhido pela rede de pessoas interessadas nos arquivos no Brasil na década de 1970 foi de associação com um nome que identificasse profissionalmente seus associados, incluindo ata de fundação, estatuto e critérios para composição dos sócios. Desse modo essa instância de ação coletiva representou a profissão e promoveu atividades de formação e aperfeiçoamento do trabalho arquivístico no país.

As condições históricas de repressão política no Brasil na década de 1970 não impediram a organização de uma associação de arquivistas realizadora na institucionalidade do campo. O associativismo profissional logo se consolidou como forma de organização da categoria.

No conjunto de realizações assumidas por esse movimento associativo, por intermédio de seu instrumento de divulgação, comemorava-se, em 1978, a institucionalização legal da profissão de arquivista, reservada aos graduados em Arquivologia. Como acontecera com a anunciada conquista do curso superior autorizado, agora seus editores divulgavam - além de se apresentarem como seus articuladores - o processo legislativo que institucionalizou a profissão. Assim, demarcaram-se suas competências e condicionou-se o título aos egressos daquele curso ${ }^{3}$.

Não se pode deixar de mencionar que, ao lado das lutas políticas, há um intrincado meandro de relações pessoais, como se pode depreender por Ástrea de Moraes e Castro (2008) que publicou textos e documentos sobre a trajetória da Arquivologia no Brasil, demarcando a sua participação no movimento associativo, a sua carreira como arquivista na Câmara dos Deputados, sobretudo, suas articulações junto ao diretor de ensino superior do Conselho Federal de Educação, Vicente Sobriño Porto, com quem teria relações pessoais, para conseguir a aprovação da graduação em Arquivologia. Também assegura que acionou as influências de Amália Lucy Geisel, filha do militar presidente da República Ernesto Geisel, para que a regulamentação da profissão acontecesse em 1978.

\footnotetext{
${ }^{3}$ Tanto na Lei no 6.546, de 4 de julho de 1978, quanto na sua regulamentação por intermédio do Decreto no 82.590, de 6 de novembro de 1978, houve a permissão do exercício das profissões de Arquivista e de Técnico de Arquivo aos profissionais que possuíam em 5 de julho de 1978, pelo menos, cinco anos ininterruptos de atividade ou dez intercalados, nos campos profissionais da Arquivologia ou da Técnica de Arquivo.
} 


\section{CONSIDERAÇÕES FINAIS}

As diferentes concepções teóricas sobre a ação coletiva privilegiam a compreensão da noção de organização da sociedade civil envolvendo o sindicalismo, as organizações não governamentais, as associações e os movimentos sociais.

Entendemos que a institucionalização do campo arquivístico no Brasil se manifesta como realização do seu movimento associativo na década de 1970 , tendo em vista que o movimento anunciava uma campanha por melhoria e aperfeiçoamento dos arquivos, tidos como depósitos de documentos amontoados. Esse movimento decorreu de um grupo de trabalho para valorizar o trabalho de arquivo que se reuniu no sétimo andar da Avenida Rio Branco, 120, Galeria dos Empregados do Comércio, no centro do Rio de Janeiro, no dia 14 de abril de 1971, envolvendo profissionais de arquivo que trabalhavam em instituições com acervos documentais de diversas naturezas e foram dados os primeiros passos para a fundação da Associação dos Arquivistas Brasileiros.

É interessante ressaltar que o surgimento desse associativismo arquivístico no Brasil é contemporâneo ao canadense, Associação dos Arquivistas do Quebec, e ao português, Associação Portuguesa de Bibliotecários, Arquivistas e Documentalistas. Isso apontaria para uma aproximação da área no Brasil às tendências internacionais naquele momento, conforme foi constatado por Marques (2011).

O associativismo exerceu relevante papel como espaço de articulação das demandas do mundo do trabalho e das reflexões sobre as questões arquivísticas, representando um sinal de interesse e mobilização nos meios profissionais em torno da integração da classe.

A profissão de arquivista encontra-se fundamentada pela Lei 6.546, de quatro de julho de 1978 e regulamentada pelo Decreto 82.590, de seis de novembro de 1978. A partir daí, consolidou-se que o escopo do trabalho arquivístico envolve o planejamento, a organização e o acompanhamento de serviços de arquivo nos processos documentais e informativos em torno de acervos arquivísticos com fins de preservação, orientado por preocupações culturais e de gestão.

O processo de profissionalização revela uma competência que vai se delimitando em torno da preocupação com a qualidade de determinado trabalho, em prol da sociedade e de sua regulação pelo Estado. Nesse sentido, a configuração do campo arquivístico no Brasil relacionar-se-ia, portanto, com a passagem da condição de ocupação à de profissão, regulamentada por lei federal e apoiada nos cursos universitários de arquivologia.

No associativismo arquivístico pode-se observar a construção de um discurso de afirmação para a ocupação específica em torno dos arquivos. Ao analisar a institucionalização 
do campo arquivístico no Brasil, verifica-se que a configuração desse campo é uma realização e também o esgotamento da agenda - do associativismo instituído através da Associação dos Arquivistas Brasileiros, em 1971, com a finalidade assumida de estabelecer um modelo nacional de institucionalização da arquivologia (curso universitário) e do arquivista (profissão de quem cursou essa graduação).

\section{Referências}

BOBBIO, Norberto; MATTEUCCI, Nicola; PASQUINO, Gianfranco (coord.). Dicionário de política. Brasília: Universidade de Brasília; São Paulo: Imprensa Oficial do Estado, 2002, 2 v.

BOSCHI, Renato Raul. A arte da associação: política de base e democracia no Brasil. São Paulo: Vértice, Editora Revista dos Tribunais; Rio de Janeiro: Instituto Universitário de Pesquisas do Rio de Janeiro, 1987.

CASTRO, Astréa de Moraes e. Arquivologia. Sua trajetória no Brasil. Brasília: Stilo, 2008.

DOUGLAS, Mary. Como as instituições pensam. São Paulo: EDUSP, 1998.

FONSECA, Vitor Manoel Marques da. No gozo dos direitos civis: associativismo no Rio de Janeiro, 1903-1916. Rio de Janeiro: Arquivo Nacional; Niterói: Muriaquitã, 2008.

FOUCAULT, Michel. A arqueologia do saber. São Paulo: Forense Universitária, 2005.

GANANÇA, Alexandre Ciconello. Associativismo no Brasil: características e limites para a construção de uma nova institucionalidade democrática participativa. 2006. Dissertação (Mestrado em Ciência Política) - Instituto de Ciência Política da Universidade de Brasília - UnB, Brasília, 2006.

GOHN, Maria da Glória. Movimentos Sociais e Redes de Mobilizações no Brasil Contemporâneo. 1a. ed. Petrópolis: Vozes, 2010. v. 1. 192 p.

GOMES, Yuri Queiroz. Processos de institucionalização do campo arquivístico no Brasil (19711978): entre a memória e a história. 2011. Dissertação (Mestrado em Memória Social) Universidade Federal do Estado do Rio de Janeiro, Rio de Janeiro, 2011.

GONZALEZ DE GOMEZ, Maria Nélida. Informação, inovação e democratização: a transferência de conhecimento e o movimento associativo. 1992. Tese (Doutorado em Comunicação) Escola de Comunicação da Universidade Federal do Rio de Janeiro - UFRJ, Rio de Janeiro, 1992.

MARQUES, Angélica Alves da Cunha. Interlocuções entre a Arquivologia nacional e a internacional no delineamento da disciplina no Brasil. 2011. Tese (Doutorado em Ciência da Informação) - Faculdade de Ciência da Informação da Universidade de Brasília - UnB, Brasília, 2011.

OLIVEIRA, Adriano Rodrigues de. $\mathbf{O}$ associativismo na região do Pontal do Paranapanema-SP: limites e possibilidades para o desenvolvimento rural. 2010. Tese (Doutorado em Geografia) - 
Universidade Estadual Paulista, Faculdade de Ciências e Tecnologia, Presidente Prudente, 2010.

RAMALHO, José Ricardo. Trabalho e sindicato: posições em debate na sociologia hoje. Dados, Rio de Janeiro, vol.43, n.4, 2000.

RAWLS, John. A Theory of Justice. Cambridge, Mass., Belknap, Harvard University Press, 1971.

SANTANA, Marco Aurélio. Entre a ruptura e a continuidade: visões da história do movimento sindical brasileiro. Revista Brasileira de Ciências Sociais. São Paulo, v. 14, n. 41.1999.

SANTANA, Marco Aurélio. Trabalhadores em movimento: o sindicalismo brasileiro nos anos 1980-1990. In: FERREIRA, Jorge, DELGADO, Lucilia de Almeida Neves (orgs.). O Brasil republicano - v. 4. Rio de Janeiro: Civilização Brasileira, 2003.

SOUZA, Katia Isabelli Melo de. Arquivista, visibilidade profissional: formação, associativismo e mercado de trabalho. Brasília: Starprint, 2011.

Submetido em: 12/2012

Aceito para publicação em: 02/2013 